\title{
Impact of Kenaf (Hibiscus cannabinus L.) Leaf, Bark, and Core Extracts on Germination of Five Plant Species
}

\author{
Charles L. Webber III ${ }^{1}$, Paul M. White Jr. ${ }^{1}$, Dwight L. Myers ${ }^{2}$, Merritt J. Taylor ${ }^{3} \&$ James W. Shrefler $^{4}$ \\ ${ }^{1}$ USDA, Agriculture Research Service, Sugarcane Research Unit, Houma, LA, USA \\ ${ }^{2}$ East Central University, Chemistry Department, Ada, OK, USA \\ ${ }^{3}$ Oklahoma State University, Division of Agriculture Sciences and Natural Resources, Department of \\ Agricultural Economics, Durant, OK, USA \\ ${ }^{4}$ Oklahoma State University, Division of Agriculture Sciences and Natural Resources, Cooperative Extension \\ Service, Durant, OK, USA \\ Correspondence: Charles L. Webber III, Research Agronomist, USDA, Agriculture Research Service, Sugarcane \\ Research Unit, Houma, LA 70360, USA. E-mail: chuck.webber@ars.usda.gov
}

Received: October 21, 2014 Accepted: November 13, $2014 \quad$ Online Published: January 15, 2015

doi:10.5539/jas.v7n2p93 URL: http://dx.doi.org/10.5539/jas.v7n2p93

\begin{abstract}
The chemical interaction between plants, which is referred to as allelopathy, may result in the inhibition of plant growth and development. The objective of this research was to determine the impact of kenaf (Hibiscus cannabinus L.) plant extracts on the seed germination of five plant species. Four concentrations $(0,16.7,33.3$ and $66.7 \mathrm{~g} / \mathrm{L}$ ) of kenaf leaf, bark, and core extracts were applied to the germination medium of redroot pigweed (Amaranthus retroflexus L.), green bean (Phaseolus vulgaris L.), tomato (Solanum lycopersicum Mill.), cucumber (Cucumis sativus L.), and Italian ryegrass (Lolium multiflorum Lam.) seeds. The treated seeds were placed in a non-illuminated incubator at $27{ }^{\circ} \mathrm{C}$. Germination was recorded after 7 days in the incubator. Seed germination decreased with increasing extract concentration for all the plant species tested, except for green bean. Tomato, cucumber, Italian ryegrass, and redroot pigweed followed similar trends in their responses to the extract source (kenaf bark, core, and leaves) and the impact of extract concentration. The research demonstrated that kenaf leaf extracts were allelopathic by reducing seed germination for tomato, cucumber, Italian ryegrass and redroot pigweed. Sensitivity to the allelopathic impact of the kenaf leaf extracts from highest to lowest was Italian ryegrass $>$ tomato $>$ redroot pigweed $>$ cucumber $>$ green bean, with reductions in percentage germination of 79\% (Italian ryegrass), 78\% (tomato), 53\% (redroot pigweed), $40 \%$ (cucumber), and $0 \%$ (green bean). Future research should pursue cultural practices to utilize these natural allelopathic materials to benefit crop production and limit weed competition, assess the impact of kenaf extracts on post-germination growth, and isolate the active ingredients in the kenaf leaf extracts that are allelopathic.
\end{abstract}

Keywords: allelopathy, cucumber, green bean, Italian ryegrass, kenaf, pestiphytology, redroot pigweed, seed germination, tomato, weed control

\section{Introduction}

\subsection{Allelopathy}

"Allelopathy" as coined and defined by Molisch (1937) is the biochemical interaction between plants, whether inhibiting or stimulating plant growth and development. Many plant species are now known to produce chemicals when released into the environment that can impact the growth and development of other plants (Rice, 1984). The demand by the general public for more naturally produced crops is a positive incentive to explore the use of natural plant chemicals to either promote crop growth and production, or inhibit weed growth and development.

\subsection{Kenaf}

Kenaf is a warm season annual fiber crop in the same family as cotton (Gossypium hirsutum L., Malvaceae) and okra (Abelmoschus esculentus L., Malvaceae) that can be successfully produced in a various areas of the United States, particularly in the southern states (Webber \& Bledsoe, 1993). The commercial use of kenaf continues to 
diversify from its historical role as a cordage crop (rope, twine, and sackcloth) to its various new applications including paper products, building materials, absorbents, and livestock feed (Webber \& Bledsoe, 1993).

Historically, kenaf has been used as a cordage crop to produce twine, rope, and sackcloth for over six millennia (Dempsey, 1975). Kenaf was first domesticated and used in northern Africa. India has produced and used kenaf for the last 200 years, while Russia started producing kenaf in 1902 and introduced the crop to China in 1935 (Dempsey, 1975). In the United States, kenaf research and production began during World War II to supply cordage material for the war effort (Wilson et al., 1965). The war not only interrupted the foreign fiber supplies from countries such as the Philippines, but the US involvement in the war also increased the use of these fibers by the US.

Once it was determined that kenaf was suited to production in the US, research was initiated to maximize US kenaf yields. As a result, scientists successfully developed high-yielding anthracnose-resistant cultivars, cultural practices, and harvesting machinery that increased fiber yields (Nieschlag et al., 1960; White et al., 1970; Wilson et al., 1965). Then in the 1950s and early 1960s, as USDA researchers were evaluating various plant species to fulfill future fiber demands in the US, it was determined that kenaf was an excellent cellulose fiber source for a large range of paper products (newsprint, bond paper, and corrugated liner board). It was also determined that pulping kenaf required less energy and chemical inputs for processing than standard wood sources (Nelson et al., 1962). More recent research and development work in the 1990s has demonstrated the plant's suitability for use in building materials (particle boards of various densities, thicknesses, with fire and insect resistance), adsorbents, textiles, livestock feed, and fibers in new and recycled plastics (injected molded and extruded) (Webber and Bledsoe 1993).

\subsection{Kenaf and Allelopathy}

Research by Russo et al. (1997a) comparing the impact of plastic and kenaf mulches on soil erosion and production of vegetable crops indicated that the kenaf mulch may have had an allelopathic influence on the growth of some vegetables. A kenaf mulching study further indicated that extracts from non-weathered kenaf plant material decreased germination of redroot pigweed, annual ryegrass, tomato, and cucumber, while having no impact on green bean germination (Russo et al., 1997b). In addition, whereas redroot pigweed germination continued to be detrimentally impacted across all mulching treatments (non-weather, 2 month weathered, and 4 month weathered kenaf) as the extract concentration increased, there appeared to be no ill effects on the other seedlings due to exposure to the weathered kenaf (Russo et al., 1997b). These research studies provided a clear indication that kenaf plant material had allelopathic characteristics, but the research did not isolate which portion of the kenaf plant, leaves or stems, were allelopathic. In addition, related species in the Malvaceae family have exhibited allelopathic activity. Chuah et al. (2011) reported that the aqueous extracts of pods of a related plant species, okra (Abelmoschus esculentus L.), inhibited goosegrass (Eleusine indica L. Gaertn) germination and seedling growth. Jalali et al. (2013) determined that aqueous leaf extracts of the common mallow (Malva sylvestris) also exhibited allelopathic activity decreasing the germination and seedling growth of blanket flower (Gaillardia pulchella), plumed cockscomb (Celosia argentea), sweet William (Dianthus barbatus). To maximize the use of allelopathic activity of kenaf as a positive influence in agriculture, it is important to isolate the portion of the kenaf plant that is most allelopathically active and determine the impact across numerous plant species. Such a situation obviously demanded further investigation. The purpose of this research was to determine which portion of the kenaf plant exhibited the greatest allelopathic activity and the impact across different species.

\section{Material and Methods}

\subsection{Kenaf Plant Material Preparations}

Mature, 186 day-old kenaf plants, were harvested at ground level in October prior to a killing frost. The plants were immediately separated into three major plant components, leaves, bark (stem bark), and core (stem core). The few flower and seed pods present were discarded and not included in the experiment. The separate plant portions (leaves, bark, and core) were then dried in a forced air oven for $48 \mathrm{~h}$ or until constant weight at $66^{\circ} \mathrm{C}$. The samples were then ground using a Thomas-Wiley Laboratory Mill with a $1 \mathrm{~mm}$ sieve.

\subsection{Kenaf Extract Preparations}

The plant materials and distilled water were added to $3000 \mathrm{ml}$ flasks and placed on a Lab-Line Orbit Shakers at $100 \mathrm{rpm}$ for $12 \mathrm{~h}$ at room temperature $\left(22^{\circ} \mathrm{C}\right)$. The samples were vacuum filtered through Whatman \# 42 filter paper twice. The samples were then diluted as needed with distilled water to produce concentrations of $66.7 \mathrm{~g} / \mathrm{L}$ (full strength), $33.3 \mathrm{~g} / \mathrm{L}$ (half strength), and $16.7 \mathrm{~g} / \mathrm{L}$ quarter strength solutions of kenaf leaf, bark, and core extracts. The $\mathrm{pH}$ for all dilutions was adjusted to 7.0 using $1 \mathrm{M} \mathrm{KOH}$ and $1 \mathrm{M} \mathrm{HCL}$. 


\subsection{Seed Germination}

Seeds of green bean (Phaseolus vulgaris L.) var. 10 Hystyle, tomato (Solanum lycopersicum Mill.), cucumber (Cucumis sativus L.) var. 403 Royal, annual Italian ryegrass (Lolium multiflorus Lam.), and redroot pigweed (Amaranthus retroflexus L.) were surface sterilized for $1 \mathrm{~min}$ using with $50 \%$ sodium hypochlorite solution. The seeds were then rinsed with water and allowed to air dry for $10 \mathrm{~min}$. Twenty-five seeds of each plant species were placed in separate Petri plates which contained $2.9 \mathrm{~cm}$ Whatman No. 2 filter papers. To each Petri plate was added $10 \mathrm{ml}$ of either kenaf plant extract (leaf, bark, or core) at each of the concentrations $[66.7 \mathrm{~g} / \mathrm{L}, 33.3 \mathrm{~g} / \mathrm{L}$, $16.7 \mathrm{~g} / \mathrm{L}$, and $0 \mathrm{~g} / \mathrm{L}$ (distilled water)]. The Petri plates were covered and placed in a non-illuminated incubator at $27^{\circ} \mathrm{C}$. Seven days later the Petri dishes were removed and seed germination was measured. Seeds were considered germinated when the seed radicle was at least the length of the width of seed of the specific plant species being measured.

This germination experiment was conducted twice. Each experiment included 3 kenaf plant extracts (leaf, bark, and core), 4 concentrations [0 (control), 16.7, 33.3 and $66.7 \mathrm{~g} / \mathrm{L}$ ], five plant species (green bean, tomato, cucumber, annual Italian ryegrass, and redroot pigweed), and 5 replications. All data were subjected to ANOVA and mean separation using LSD with $\mathrm{P}=0.05$ (SAS Inc., SAS, Ver. 9.0, Cary, NC).

\section{Results and Discussion}

\subsection{Statistical Analysis}

Statistical analysis determined that there were significant interactions among plant species (green bean, tomato, cucumber, Italian ryegrass, and redroot pigweed), between experiments (1 and 2), among sources of kenaf extracts (bark, core, and leaf) and extract concentration $(0,16.7,33.3$ and $66.7 \mathrm{~g} / \mathrm{L})$, therefore the results will be discussed by plant species with each interaction addressed separately.

\subsection{Green Bean}

No significant interactions were detected between or among the experimental factors (plant parts, extract concentrations, and experiments) for green bean germination. As a result, green bean data will be discussed averaged across plant parts, extract concentration, and years (Table 1). The only differences due to main affects for green bean germination were observed when comparing the source of the plant extract. The core extracts reduced seed germination compared to the bark and leaf extract. And, although the core extract did reduce germination by $8.4 \%$ and $5.5 \%$ compared to the bark and core extracts, respectively, the decrease was only $3.7 \%$ less than the control $(76.8 \%), 0 \mathrm{~g} / \mathrm{L}$ concentration (Table 1). No differences were observed among extract concentrations or between the experiments for green bean germination. Although these results were consistent with earlier research by Russo et al. (1997b), where the green bean germination was the least detrimentally affected by kenaf extracts, the current research finding of decreased green bean germination to core, but not other extracts indicates that the kenaf core is potentially the best location for isolating detrimental allelopathic chemicals for green beans. There is a slight beneficial impact of the kenaf bark and leaf extracts on seed germination, which probably explains the trend for increasing green bean germination observed by Russo et al. (1997b) when green bean seeds were exposed to increasing rates of whole stalk kenaf (leaves, bark, and core).

Table 1. Influence of kenaf plant extracts (bark, core, and leaves) and extract concentrations $(0,16.7,33.3$, and $66.7 \mathrm{~g} / \mathrm{L}$ ) on green bean germination

\begin{tabular}{|c|c|c|c|c|c|}
\hline Kenaf lant part ${ }^{\mathrm{Z}}$ & Germination & Extract oncentration $^{\mathrm{Y}}$ & Germination & Experiment $^{\mathrm{X}}$ & Germination \\
\hline & $(\%)$ & & $(\%)$ & $\#$ & $(\%)$ \\
\hline Bark & $81.5 \mathrm{a}^{\mathrm{W}}$ & $0 \mathrm{~g} / \mathrm{L}$ & $76.8 \mathrm{a}$ & 1 & $78.6 \mathrm{a}$ \\
\hline Core & $73.1 \mathrm{~b}$ & $16.7 \mathrm{~g} / \mathrm{L}$ & $76.7 \mathrm{a}$ & 2 & 76.9 a \\
\hline \multirow[t]{2}{*}{ Leaves } & $78.6 \mathrm{a}$ & $33.3 \mathrm{~g} / \mathrm{L}$ & $79.6 \mathrm{a}$ & & \\
\hline & $66.7 \mathrm{~g} / \mathrm{L}$ & $77.9 \mathrm{a}$ & & & \\
\hline
\end{tabular}

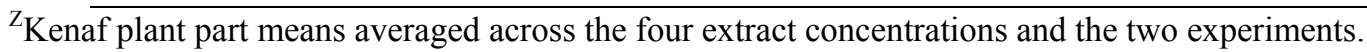

${ }^{\mathrm{Y}}$ Extract concentration means averaged across kenaf plant parts and experiments.

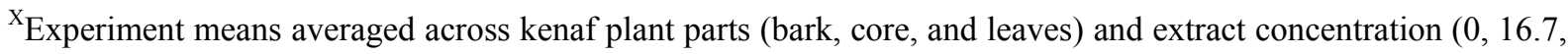
33.3, and $66.7 \mathrm{~g} / \mathrm{L})$.

${ }^{\mathrm{w}}$ Means in a column within a main effect (kenaf plant part, extract concentration, and experiment) followed by the same lower case letter are not significantly different at $\mathrm{P} \leq 0.05$, ANOVA. 


\subsection{Tomato}

Two significant interactions were detected for tomato germination in relation to the source of the kenaf extract (bark, core, and leaves). The main effect plant parts interacted separately with the extract concentrations and with the experiments. Therefore, tomato germination will be discussed separated by plant parts, extract concentrations, and experiments (Table 2). Although differences did occur among the sources of the plant extracts and between experiments, the percentage of seed germination decreased as extract concentration increased for all sources of plant extracts and for both experiments. The greatest decrease was observed in Experiments 1 and 2 for the leaf extract, where germination decreased from $88 \%$ to $0 \%$ germination for Experiment 1, and $89.6 \%$ germination to $14.4 \%$ germination in Experiment 2. Although the core and bark did decrease germination as the extract concentrations increased, the decrease was only $12.8 \%$ (Experiment 1 ) and 9.6\% (Experiment 2) for the core extract, and 14.4\% (Experiment 1) and 6.4\% (Experiment 2) for the bark extract, comparing the $0 \mathrm{~g} / \mathrm{L}$ concentration (control) to $66.7 \mathrm{~g} / \mathrm{L}$ concentrations. These results reinforce earlier research which identified tomato as being sensitive to kenaf plant extracts (Russo et al., 1997b), while the current research provides insight into which portion of the kenaf plant, the leaves, has the greatest impact on seed germination for tomato. It is interesting to note that all portions of the above ground kenaf plant were allelopathically active with tomato.

Table 2. Impact of kenaf core, bark, and leaf extracts and extract concentrations on percentage of tomato seed germination

\begin{tabular}{|c|c|c|c|c|c|c|c|c|c|c|c|c|}
\hline \multirow{3}{*}{ Extract Concentration } & \multicolumn{4}{|c|}{ Core $^{z}$} & \multicolumn{4}{|c|}{ Bark } & \multicolumn{4}{|c|}{ Leaves } \\
\hline & \multicolumn{4}{|c|}{ Experiment } & \multicolumn{4}{|c|}{ Experiment } & \multicolumn{4}{|c|}{ Experiment } \\
\hline & \multicolumn{2}{|c|}{1} & \multicolumn{2}{|c|}{2} & \multicolumn{2}{|c|}{1} & \multicolumn{2}{|c|}{2} & \multicolumn{2}{|c|}{1} & \multicolumn{2}{|c|}{2} \\
\hline & $\%$ & & $\%$ & & $\%$ & & $\%$ & & $\%$ & & $\%$ & \\
\hline $0 \mathrm{~g} / \mathrm{L}$ & 88.0 & $\mathrm{a}^{\mathrm{Y}}$ & 89.6 & a & 88.0 & $\mathrm{a}$ & 89.6 & $\mathrm{a}$ & 88.0 & $\mathrm{a}$ & 89.6 & $\mathrm{a}$ \\
\hline $16.7 \mathrm{~g} / \mathrm{L}$ & 91.2 & $\mathrm{a}$ & 88.0 & $\mathrm{a}$ & 87.2 & $\mathrm{a}$ & 90.4 & $\mathrm{a}$ & 78.4 & $b$ & 88.0 & $\mathrm{a}$ \\
\hline $33.3 \mathrm{~g} / \mathrm{L}$ & 80.8 & $\mathrm{~b}$ & 80.0 & $\mathrm{~b}$ & 88.0 & $\mathrm{a}$ & 82.4 & $\mathrm{~b}$ & 64.0 & $\mathrm{c}$ & 72.8 & $\mathrm{~b}$ \\
\hline $66.7 \mathrm{~g} / \mathrm{L}$ & 75.2 & $\mathrm{c}$ & 80.0 & $\mathrm{~b}$ & 73.6 & $\mathrm{~b}$ & 83.2 & $\mathrm{~b}$ & 0.0 & d & 14.4 & $\mathrm{c}$ \\
\hline
\end{tabular}

${ }^{\mathrm{Z}} \mathrm{Extract}$ concentration means averaged across either the kenaf core, bark, or leaf extracts.

${ }^{\mathrm{Y}}$ Means in a column followed by the same lower case letter are not significantly different at $\mathrm{P} \leq 0.05$, ANOVA.

\subsection{Cucumber, Italian Ryegrass, and Redroot Pigweed Interaction Analysis}

The statistical analysis did not detect interactions between the kenaf extract sources (bark, core, and leaf) or extract concentrations $(0,16.7,33.4$, and $66.7 \mathrm{~g} / \mathrm{L})$ and the experiments, therefore the results will be discussed averaged across experiments (Table 3 ).

\subsubsection{Cucumber}

The kenaf leaf extract was the only source of extract that decreased cucumber seed germination as the extract concentration increased (Table 3). This is in contrast to the kenaf bark and core extract concentrations, which actually elevated germination at the $16.7 \mathrm{~g} / \mathrm{L}$ rate. This data helps explain earlier research by Russo et al. (1997b) where cucumber germination increased as whole stalk (leaves, bark, and core) extract concentrations increased. Russo et al. (1997b) were using the above ground portion of 193 day-old kenaf plants for their mulching study, which would contain disproportionate greater amounts of stalks (bark and core) than leaves, due to the naturally occurring kenaf leaf abscission as the plant matures through the growing season. The greater proportion of bark and core plant material in mulching experiments explains why they only observed a beneficial impact in reference to cucumber germination (Russo et al., 1997b) compared to our mixed response to the kenaf extracts depending of the source of the kenaf extracts.

\subsubsection{Italian Ryegrass and Redroot Pigweed}

Italian ryegrass and redroot pigweed response to the source of kenaf extract and extract concentrations were very similar (Table 3). Seeds from both of these plants were very sensitive to kenaf plant extracts. Seed germination for both plants decreased as the extract concentrations increased, independently of the source of the kenaf 
extract, but with the greatest decrease observed for kenaf leaf extracts. Italian ryegrass germination decreased by $12.2 \%, 14.4 \%$, and $78.4 \%$ from the $0 \mathrm{~g} / \mathrm{L}$ concentration (control) to the $66.7 \mathrm{~g} / \mathrm{L}$ concentration for the bark, core, and leaf extracts, respectively. The impact on redroot pigweed germination was also dramatic, decreasing $41.2 \%$, $24.0 \%$, and $53.2 \%$ from the $0 \mathrm{~g} / \mathrm{L}$ concentration to the $66.7 \mathrm{~g} / \mathrm{L}$ concentration for the bark, core, and leaf extracts, respectively. These results are consistent with Russo et al. (1997b) where the greatest detrimental impact to kenaf extracts was observed with Italian ryegrass and redroot pigweed, while the current research further illuminated which portion of the kenaf plant created the greatest impact, the leaves.

Table 3. Impact of the kenaf extract source (core, bark, and leaf) and extract concentration on cucumber, Italian ryegrass, and redroot pigweed germination percentage

\begin{tabular}{|c|c|c|c|c|}
\hline Kenaf extract & & Cucumber & Italian Ryegrass & Redroot Pigweed \\
\hline \multirow[t]{8}{*}{ Bark } & Concentration $^{\mathrm{Z}}$ & $\%$ & $\%$ & $\%$ \\
\hline & $0 \mathrm{~g} / \mathrm{L}$ & $71.6 c^{x}$ & $84.4 \mathrm{a}$ & $58.0 \mathrm{a}$ \\
\hline & $16.7 \mathrm{~g} / \mathrm{L}$ & $76.4 \mathrm{a}$ & $75.2 \mathrm{~b}$ & $40.4 \mathrm{~b}$ \\
\hline & $33.3 \mathrm{~g} / \mathrm{L}$ & $73.6 \mathrm{~b}$ & $70.4 \mathrm{c}$ & $26.0 \mathrm{c}$ \\
\hline & $66.7 \mathrm{~g} / \mathrm{L}$ & $72.4 \mathrm{bc}$ & $71.2 \mathrm{c}$ & $16.8 \mathrm{~d}$ \\
\hline & Experiment $^{\mathrm{Y}}$ & $\%$ & $\%$ & $\%$ \\
\hline & 1 & $73.0 \mathrm{a}$ & $73.4 \mathrm{a}$ & $39.0 \mathrm{a}$ \\
\hline & 2 & $74.0 \mathrm{a}$ & $77.2 \mathrm{a}$ & $31.6 \mathrm{~b}$ \\
\hline \multirow[t]{8}{*}{ Core } & Concentration & $\%$ & $\%$ & $\%$ \\
\hline & $0 \mathrm{~g} / \mathrm{L}$ & $71.6 \mathrm{~b}$ & $84.4 \mathrm{a}$ & $58.0 \mathrm{a}$ \\
\hline & $16.7 \mathrm{~g} / \mathrm{L}$ & $82.0 \mathrm{a}$ & $80.0 \mathrm{~b}$ & $47.2 \mathrm{~b}$ \\
\hline & $33.3 \mathrm{~g} / \mathrm{L}$ & $72.8 \mathrm{~b}$ & $71.6 \mathrm{c}$ & $42.8 \mathrm{~b}$ \\
\hline & $66.7 \mathrm{~g} / \mathrm{L}$ & $72.8 \mathrm{~b}$ & $70.0 \mathrm{c}$ & $34.0 \mathrm{c}$ \\
\hline & Experiment & $\%$ & $\%$ & $\%$ \\
\hline & 1 & $74.4 \mathrm{a}$ & $78.2 \mathrm{a}$ & $47.6 \mathrm{a}$ \\
\hline & 2 & $75.2 \mathrm{a}$ & $74.8 \mathrm{a}$ & $43.4 \mathrm{~b}$ \\
\hline \multirow[t]{8}{*}{ Leaves } & Concentration & $\%$ & $\%$ & $\%$ \\
\hline & $0 \mathrm{~g} / \mathrm{L}$ & $71.6 \mathrm{a}$ & $84.4 \mathrm{a}$ & $58.0 \mathrm{a}$ \\
\hline & $16.7 \mathrm{~g} / \mathrm{L}$ & $70.8 \mathrm{a}$ & $73.6 \mathrm{~b}$ & $32.0 \mathrm{~b}$ \\
\hline & $33.3 \mathrm{~g} / \mathrm{L}$ & $61.6 \mathrm{~b}$ & $48.4 \mathrm{c}$ & $21.2 \mathrm{c}$ \\
\hline & $66.7 \mathrm{~g} / \mathrm{L}$ & $32.0 \mathrm{c}$ & $6.0 \mathrm{~d}$ & $4.8 \mathrm{~d}$ \\
\hline & Experiment & $\%$ & $\%$ & $\%$ \\
\hline & 1 & $59.8 \mathrm{a}$ & $54.2 \mathrm{a}$ & $31.4 \mathrm{a}$ \\
\hline & 2 & $58.2 \mathrm{a}$ & $52.0 \mathrm{a}$ & $26.6 \mathrm{~b}$ \\
\hline
\end{tabular}

${ }^{\mathrm{Z}}$ Extract concentration means averaged across either the kenaf core, bark, or leaf extracts across 2 experiments.

${ }^{Y}$ Experiment means averaged across extract concentration.

${ }^{\mathrm{x}}$ Means in a column within either extract concentration, extract source or experiment followed by the same lower case letter are not significantly different at $\mathrm{P} \leq 0.05$, ANOVA. 


\section{Conclusions}

Seed germination decreased with increasing extract concentration for all the plant species tested, except for green bean. Tomato, cucumber, Italian ryegrass, and redroot pigweed followed similar trends in their responses to the extract source (kenaf bark, core, and leaves) and the impact of extract concentration. The research demonstrated that kenaf leaf extracts were allelopathic by reducing seed germination for tomato, cucumber, Italian ryegrass and redroot pigweed. Sensitivity to the allelopathic impact of the kenaf leaf extracts from highest to lowest was Italian ryegrass $>$ tomato $>$ redroot pigweed $>$ cucumber $>$ green bean, with reductions in percentage germination of $78.4 \%$ (Italian ryegrass), $77.6 \%$ (tomato), $53.2 \%$ (redroot pigweed), 39.6\% (cucumber), and $0 \%$ (green bean). The research also indicated that kenaf core and bark extracts may provide slight beneficial impact of cucumber germination at the low extract concentration $(16.7 \mathrm{~g} / \mathrm{L})$. Future research should pursue cultural practices to utilize these natural allelopathic materials to benefit crop production and limit weed competition, assess the impact of kenaf extracts on post-germination growth, and isolate the active ingredients in the kenaf leaf extracts that are allelopathic.

\section{References}

Chuah, T. S., Tiun, S. M., \& Ismail, B. S. (2011). Allelopathic potential of crops on germination and growth of goosegrass (Eleusine indica L. Gaertn) weed. Allelopathy Journal, 27(1), 33-42.

Dempsey, J. M. (1975). Fiber Crops. The Univ. Presses of Florida, Gainesville.

Jalali, M, Gheysari, H., Azizi, M., Zahedi, S. M., \& Moosavi, S. A. (2013). Allelopathic potential of common mallow (Malva sylvestris) on the germination and the initial growth of blanket flower, plumed cockscomb and sweet William. Intl. J. Agri. Crop Sci., 5(15), 1638-1641.

Molisch, H. (1937). Der Einfluss einer pflanze auf die andere. Allelopathic Fischer, Jena.

Nieschlag, H. J., Nelson, G. H., Wolff, I. A., \& Perdue, R. E. Jr. (1960). A search for new fiber crops. TAPPI, 43, 193-201.

Nelson, G. H., Nieschlag, H. J., \& Wolff, I. A. (1962). A search for new fiber crops, V. Pulping studies on kenaf. TAPPI, 45(10), 780-786.

Rice, E. L. (1984). Allelopathy (2nd ed., p. 422). Acedemic Press, New York.

Russo, V. M., Cartwright, C., \& Webber III, C. L. (1997a). Mulching effects on erosion of soil beds and on yield of autumn and spring planted vegetables. Biological Agriculture and Horticulture, 14, 85-93. http://dx.doi.org/10.1080/01448765.1997.9754799

Russo, V. M., Webber III, C. L., \& Myers, D. L. (1997b). Kenaf extract affects germination and post-germination development of weed, grass and vegetable seeds. Ind. Crops Prod., 6, 59-69. http://dx.doi.org/10.1016/S0926-6690(96)00206-3

Webber III, C. L., \& Bledsoe, R. E. (1993). Kenaf: Production, harvesting, and products. In J. Janick \& J. E. Simon (Eds.), New Crops (pp. 416-421). New York: Wiley.

White, G. A., Cummins, D. G., Whiteley, E. L., Fike, W. T., Greig, J. K., Martin, J. A., .. Clark, T. F. (1970). Cultural and harvesting methods for kenaf. USDA Prod. Res. Rpt. (Vol. 113). Washington, DC.

Wilson, F. D., Summers, T. E., Joyner, J. F., Fishler, D. W., \& Seale, C. C. (1965). 'Everglades 41' and 'Everglades 71', two new cultivars of kenaf (Hibiscus cannabinus L.) for the fiber and seed. Florida Agr. Expt. Sta. Cir. S-168.

\section{Copyrights}

Copyright for this article is retained by the author(s), with first publication rights granted to the journal.

This is an open-access article distributed under the terms and conditions of the Creative Commons Attribution license (http://creativecommons.org/licenses/by/3.0/). 